\title{
Estudo sobre o uso do cânone linguístico-literário na Gramática Fundamental da Língua Portuguesa, de Adriano da Gama Kury
}

\author{
Ariane Wust de Freitas Francischini ${ }^{\mathrm{i}}$
}

\begin{abstract}
RESUMO
Nos estudos acadêmicos acerca da gramaticografia brasileira, é inevitável abordarmos a relação existente entre língua e literatura no que tange à análise das obras referenciais, com o intuito de compreender o âmago ideológico e linguístico que fundamenta o saber gramatical. Dessa forma, nos propusemos a realizar o inventário do Cânone LinguísticoLiterário e a descrever as abonações da Gramática Fundamental da Língua Portuguesa Ensino Médio, de Adriano da Gama Kury, assim como investigar a conjuntura histórica da gramaticografia brasileira a partir do processo de construção dessa obra. A Gramática Fundamental da Língua Portuguesa, assim como os manuais de língua publicados na mesma época, sofreu influência das diretrizes fixadas na NGB e na Lei no 5692/71. Portanto, a execução deste tipo de pesquisa oportuniza também a caracterização das influências históricas na gramaticografia brasileira e, consequentemente, o retrato da Língua Portuguesa usada em um contexto determinado.
\end{abstract}

Palavras-chave: Gramática; Língua Portuguesa; Cânone; Linguístico; Literário.

\begin{abstract}
In academic studies about Brazilian grammar, we inevitably address the relationship between language and literature, analyzing referential works to understand the ideological and linguistic core that sustains grammatical knowledge. Therefore, we aim to conduct the Linguistic-Literary Canon inventory and to describe the accreditations of the Fundamental Grammar of the Portuguese Language - High School by Adriano da Gama Kury, as well as to investigate the historical context of Brazilian grammar from the construction process of this work. Besides the Fundamental Grammar of the Portuguese Language, the language manuals published at the same period were also influenced by the guidelines established in the NGB and Law No. 5692/71. Therefore, carrying out this type of research also provides opportunities for the characterization of historical influences on Brazilian grammaticography and consequently, the representation of the Portuguese language used in a given context.
\end{abstract}

Keywords: Grammar; Portuguese Language; Canon; Linguistic; Literary.

\footnotetext{
${ }^{i}$ Mestra em Letras pela Universidade Estadual de Mato Grosso do Sul (UEMS) e doutoranda em Letras, especialidade Língua Portuguesa pela Universidade do Estado do Rio de Janeiro (UERJ). Professora das redes municipal e estadual de ensino em Mato Grosso do Sul e professora colaboradora do Núcleo de Ensino de Línguas da UEMS/NEL.

ORCID: https://orcid.org/0000-0003-3786-1237 | aajaraguari@gmail.com
} 


\section{INTRODUÇÃO}

A leitura e anotação dos bons escritores será o melhor meio de guiar-se neste particular. (Kury, 1972, p. 88)

Definida genericamente como a "ciência que estuda o sistema de uma determinada língua" (CARRETER, 1974), a gramática, além de ser abordada sob diversas perspectivas, retrata os aspectos históricos, sociais e culturais no interior de uma determinada sociedade. Assim, desvelar as fontes nas quais os gramáticos teriam se inspirado para escrever suas obras e o perfil dos autores escolhidos é uma oportunidade para caracterizar as influências históricas na gramaticografia.

No âmbito dos estudos da gramaticografia brasileira, observamos trabalhos semelhantes a essa proposta, mas nenhum que tenha investigado o mesmo corpus. Para tanto, definimos como objeto de estudo a Gramática Fundamental da Língua Portuguesa - Ensino Médio, de Adriano da Gama Kury, publicada em 1972 pela Editora Lisa (Livros Irradiantes S.A.); e, como corpus de análise, as citações literárias selecionadas pelo autor para exemplificar e atestar os fatos da língua. Neste contexto, preconizamos realizar o inventário do cânone linguístico-literário escolhido por Kury (1972) como abonações representativas de excelência linguística. Temos ainda o objetivo de observar em que medida esta pesquisa colaborará para a investigação e a expansão dos estudos da gramaticografia brasileira, no que se refere à compreensão dos fundamentos ideológicos, linguísticos e históricos, base do nosso saber gramatical nos mais variados campos interpretativos.

Não nos propusemos a discutir, neste momento, a relevância científica ou contribuição pedagógica de nosso objeto, mas a discorrer sobre o uso do Cânone Linguístico-Literário, que podemos chamar de "atestado de qualidade e justificador da seleção do autor e do exemplo por parte do gramático" (HENRIQUES, 2004, p. 117). Cabe mencionar que, durante a realização desta pesquisa, sentimos a necessidade de abordar brevemente a vida e a obra do autor, bem como a conjuntura histórica que influenciou a gramaticografia brasileira e, em consequência, a ação de ambas na produção escrita do texto em estudo. Assim, dividimos este artigo em duas partes: a contextualização dos fatos abordados, e o levantamento e a análise do corpus selecionado.

\section{CONTEXTUALIZAÇÃO DOS FATOS ABORDADOS}




\subsection{Aspectos históricos: gramaticografia e legislação}

Teoricamente, podemos balizar a gramática como uma "ciencia que estudia el sistema de una lengua" (CARRETER, 1974, p. 213); ou, em termos mais específicos, um "system by wich the words and morphemes of a language are organized into larger units, particulary into sentences, perceived as existing independently of any attempt at discribing it" (TRASK, 1993, p. 121). No domínio dos estudos sobre a linguagem humana, desde a Antiguidade Clássica, a gramática pode ser abordada sob perspectivas diversas, sendo sua história uma das mais instigantes e estimulantes de toda a humanidade (STEFANINI, 1994; ROCAPONS, 1976; MATTOS E SILVA, 2000). O estudo da história da gramaticografia, além de retratar os aspectos históricos, sociais e culturais incutidos no interior de uma sociedade e decorrentes do seu processo de construção, também desvela fontes nas quais os gramáticos teriam se inspirado para escrever suas obras.

Cabe ressaltar a expansão, ainda que incipiente, dos estudos acadêmicos acerca da gramaticografia brasileira com o intuito de compreender o âmago ideológico e linguístico que fundamenta o saber gramatical, assim como as principais linhas teóricas e práticas que conduziram o processo de consolidação da escrita no país.

Isso posto, procuramos estabelecer a conjuntura histórica da gramaticografia brasileira a partir do autor Adriano da Gama Kury e de duas das suas produções, a Pequena Gramática para explicação da Nova Nomenclatura Gramatical e a obra objeto deste estudo, a Gramática Fundamental da Língua Portuguesa - Ensino Médio. Para tanto, apresentamos um recorte dos estudos gramaticais a partir da publicação da Portaria no 36 de 29 de janeiro de 1959, do Ministério da Educação (MEC), que instituiu a Norma Gramatical Brasileira (NGB). Outro fato histórico que colaborou para a mudança de paradigma na gramaticografia brasileira foi a promulgação da Lei de Diretrizes e Bases da Educação no 5692, de 11 de agosto de 1971, conhecida como a "Reforma do ensino" e instituída no seio da ditadura militar no Brasil. De modo paradoxal a esse regime político, a lei tinha como princípio a flexibilidade, vista por Saviani como oportunismo dos donos do poder: 
[...] o princípio de flexibilidade foi instrumento importante para preservar no âmbito educacional o arbítrio que caracterizava o poder então exercido. Com efeito, pela flexibilidade, as autoridades governamentais evitavam se sujeitar a definições legais mais precisas que necessariamente imporiam limites à sua ação, ficando livres para impor à nação os programas educacionais de interesse dos donos do poder. E com a vantagem de facilitar a busca de adesão e apoio daqueles mesmos sobre os quais eram impostos os referidos programas. (SAVIANI, 1997, p. 27)

Nesta fase da gramaticografia, a NGB promoveu uma considerável mudança na construção das gramáticas brasileiras, visto que interferiu diretamente no modus faciendi com a determinação de um estrito padrão conceitual e taxonômico. Um processo que resultou na redução do papel social do gramático, na medida em que, ao "impor uma transformação e uma padronização do discurso gramatical, obrigou-o a ser uma espécie de comentarista da nomenclatura" (BALDINI, 1998).

Cenário do lançamento da obra, best-seller nos estudos gramaticais brasileiros, a Pequena Gramática para a Explicação da Nova Nomenclatura Gramatical, publicada pela editora Agir, em 1959, evidenciou Adriano da Gama Kury, no contexto acadêmico. Detentora de poder legal, a NGB representou o encerramento de uma etapa de nossa gramaticografia com implicações consideráveis até mesmo no estatuto autoral do gramático (ORLANDI, 2002), marcando a decadência do ideário gramatical assentado na normatividade dos fatos da língua, bem como assinalou a intercorrência de teorias linguísticas, com o advento do estruturalismo. Entre 1959 e 1971, sob influência da NGB, Kury denotou uma intensa produção acadêmica com a publicação de cinco livros, inúmeros artigos e resenhas.

No momento histórico em que essa legislação foi decretada, aludiam no ensino de Língua Portuguesa duas concepções de linguagem respaldadas pelo Artigo $4^{\circ}, \S 2$ da referida lei, ao mencionar que "no ensino de $1^{\circ}$ e $2^{\circ}$ graus dar-se-á especial relevo ao estudo da língua nacional, como instrumento de comunicação e como expressão da cultura brasileira", representando, respectivamente, o normativismo e o estruturalismo. Vale ressaltar que, devido à necessidade de fixar a norma culta, a concepção de língua como expressão do pensamento norteou os manuais de ensino até final do século XIX, propondo uma aprendizagem mecânica que alinhavasse ao autoritarismo da ditadura militar, modelo de ensino proposto pela lei e pautado no tecnicismo.

A Lei $n^{\circ}$ 5692/71 reorganizou o ensino e alterou as denominações das disciplinas para efeito da obrigatoriedade atribuída ao núcleo-comum, incluindo como conteúdos 
específicos e matérias fixadas, comunicação e expressão. Destarte, resgatava o nome "Língua Portuguesa", mas os críticos da época apontavam um "rebaixamento", pois o termo deixava de nomear a disciplina ou matéria e virava simples "conteúdo" (HENRIQUES, 2020, p. 76).

Nessa perspectiva, evidenciamos que o contexto sociopolítico da época revelava a preocupação do governo militar com a formação técnica, cabendo aos educadores executar as medidas adotadas e formar a mão-de-obra demandada pela sociedade tecnocrata. A Legislação mencionava ainda, em seu Art. $1^{\circ}$, o objetivo de proporcionar ao educando a formação necessária ao desenvolvimento de suas potencialidades como elemento de autorrealização, qualificação para o trabalho e preparo para o exercício da cidadania, ficando evidente a preocupação com a formação profissional, justificada pelo momento histórico.

Essa legislação alterou consideravelmente a estrutura do ensino no Brasil, colaborando para a fragmentação na formação do indivíduo e a profissionalização compartimentada. Ainda que regulado pelo princípio da flexibilidade e pelo exercício da cidadania, o texto da lei evidenciava a discrepância com os objetivos propostos ao revelar o autoritarismo da ditadura militar por meio de expressões como: "será obrigatória”, "será fixada", "será instituída obrigatoriamente", dentre outras.

Sem sombra de dúvidas, o texto da Lei $\mathrm{n}^{\circ}$ 5.692/71 foi marcado pela história de seu tempo e influenciou a produção de manuais normativos para o ensino de língua até o final do século XIX e permanece, ainda hoje, nas visões mais conservadoras, assinaladas pelo uso da língua padrão e verificadas nos cânones literários. Para Henriques (1998, p. 27), "não compete às gramáticas possuir um tom ditatorial, e a relutância no acolhimento das novidades circulantes nos diversos usos de uma língua histórica”.

Sob este panorama, em 1972, Kury redigiu e publicou a obra, objeto deste estudo, a Gramática da Língua Portuguesa - Ensino Médio, que, assim como as demais produções da época, foi influenciada por esse momento histórico. Desse modo, observar qual o perfil dos autores escolhidos por Kury para compor os textos da sua obra é, também, como mencionado no início do texto, momento oportuno para verificar as influências históricas na gramaticografia brasileira.

\section{LEVANTAMENTO E ANÁLISE DO CORPUS SELECIONADO}




\subsection{O Cânone}

Para melhor entendimento deste estudo, torna-se importante compreender o conceito de cânone e seu uso linguístico e literário. Segundo Perrone-Moisés (1968, p. 61), a palavra "cânone" vem do grego kánon, do latim canon, e significa "regra" ou "vara de medir”. Sua primeira utilização ocorreu no domínio religioso e tinha como objetivo eleger os escritos canônicos, ou cânone bíblico, a partir da seleção de textos com padrão moralmente corretos e considerados "inspiração divina", segundo a análise dos líderes religiosos.

Nesse mesmo cenário, serviu também para nomear seres humanos considerados santos, pelo ato da canonização instituído pela igreja católica. Na sua essência, a palavra "cânone" passou a significar um conjunto de elementos elitizados, lista de destaque ou catálogo importante, conferindo distinção entre o que é comum e o que merece destaque, "legitimando os cânones mediante a exclusão de agentes considerados inferiores, rejeitados ou não aptos” (MOREIRA, 2011, p. 17).

Por esse prisma, o cânone literário implica um conjunto de obras dotadas de valores e grandezas universais, textos considerados clássicos e legitimados por autoridades reconhecidas. A formação de um cânone tem uma função específica: "preservar uma estrutura de valores que seja considerada como fundamental para o indivíduo ou para o grupo, constituindo uma norma e está intimamente relacionado com o contexto histórico e cultural" (CORRÊA, 1995, p. 324).

Neves (2005, p. 645-646) enfatiza que "a relação estabelecida na descrição da língua dentro do texto literário é consequência do próprio processo tecnológico de construção deste saber". Assim, o primeiro papel a ser apontado na constituição do padrão de linguagem em uma nação é seguramente o da literatura, uma vez que está no:

texto literário à plena funcionalidade da linguagem ou a realização de suas possibilidades, de suas virtualidades, compreendendo que a língua literária não se encerra em limites comportamentais, mas percorre as várias possibilidades de uso. (COSERIU, 1993, p. 39)

Dessa forma, compreendemos que o uso da palavra cânone foi trazido do contexto religioso para o literário, e do literário para o linguístico por meio da gramaticografia. Cabe ressaltar que, mesmo empregada em diferentes áreas, seu uso respeita a base de 
significação do vocabulário original. Segundo Henriques, o Cânone Linguístico-Literário corresponde a:

[...] hábitos tradicionais de adotar como modo exemplificador de regras e descrições a transcrição de trechos de autores da literatura [...]. Deve-se daí concluir que o filólogo fazia suas escolhas com o zelo de quem precisava atestar suas explicações com passagem que representassem, de um lado, o fato da língua a ser exposto e, de outro, o prestígio do escritor citado perante a comunidade de qualidade linguístico-literária, justificador da seleção do autor e do exemplo por parte do gramático. (HENRIQUES, 2004, p. 117)

De acordo com o histórico dos estudos linguísticos brasileiros, a tradição gramatical no país, sob inspiração da gramaticografia inglesa e francesa, apoiava-se em corpora literários, "considerados textos consagrados e adequados ao ensino da língua escrita" (CAVALIERE, 2000).

Conforme Henriques (1998, p. 26), havia uma espécie de cumplicidade linguístico-literária que atribuía ao autor um nível de excelência diante do eventual leitor da obra teórica, como alguém já possuidor de uma "autoridade literária", e que, ao ser selecionado pelo gramático, também obterá uma proclamada "autoridade linguística justificando a escolha das exemplificações para atestar os fatos da língua”.

\footnotetext{
Consideremos esses exemplos e abonações encontrados em nossas gramáticas e como e por que seu autor julgou tais exemplos e abonações representativos de uma específica competência linguística ou de um determinado nível de linguagem, às chamadas "norma literária". Em outras palavras: haveria alguma forma de identificar escritores que atestam com suas frases a "boa linguagem" e que são assim considerados porque atingiram algum grau de "nobreza literária", título sempre estabelecido segundo a ótica da comunidade acadêmica [...]. (HENRIQUES, 1998, p. 26)
}

Ainda segundo o autor, é inevitável abordarmos a relação existente entre língua e literatura, no que tange aos estudos das obras referenciais brasileiras no campo gramatical e suas respectivas exemplificações linguístico-literárias.

\subsection{Do objeto, corpus e análise}

Assim como nos inventários realizados por Henriques, cito "O cânone Linguístico-Literário das gramáticas de Celso Cunha", "O cânone Linguístico-Literário na Moderna Gramática Portuguesa, de Evanildo Bechara", e "O cânone Linguístico- 
Literário segundo a Gramática Normativa da Língua Portuguesa de Carlos Henrique da Rocha Lima”. Observamos também um perfil canonizador distinto, seja pelo contexto histórico ou pelo corpus de exemplificação selecionado.

A Gramática Fundamental da Língua Portuguesa de Adriano da Gama Kury, publicada em 1972 pela Editora Lisa, da mesma maneira que os demais manuais de língua veiculados pós-NGB e promulgação da Lei $n^{\circ} 5692 / 71$, sofreu forte influência dos aspectos históricos da época e, em decorrência, apresenta a concepção de língua fundamentada no estruturalismo e na abordagem tradicional do ensino.

Kury escreveu a Gramática Fundamental da Língua Portuguesa, como especificado em seu prefácio, dedicada ao ensino de nível médio da língua portuguesa do Brasil, abordando três aspectos: 1) construção das frases, orações e períodos; 2) classificação, flexão e formação das palavras; 3) sons distintivos ou fonemas; organizada em quatro partes, respectivamente: sintaxe, significação das palavras, morfologia e fonologia. Nas duas primeiras, valeu-se da modalidade escrita literária contemporânea; já nas últimas partes, recorreu à linguagem falada pelas pessoas consideradas cultas da década de 1970 nas cidades do Rio de Janeiro e São Paulo, abandonando a fidelidade e a homogeneidade do corpus com a descrição da língua escrita literária.

Para a sua época, a obra é considerada inovadora no tocante ao aspecto do leitor destinatário e do corpus selecionado para exemplificar e atestar a descrição dos fatos da língua, mediante proposição de novas fontes literárias de autores brasileiros, bem como a linguagem culta falada, ambas exemplificadas por meio de corpus ampliado em relação às demais gramáticas tradicionais.

Apesar de recorrer também à linguagem culta falada na terceira e na quarta parte da sua obra, Kury não rompeu definitivamente com o modelo clássico, pois privilegiou em sua gramática, sobretudo no capítulo destinado ao estudo da Sintaxe, um corpora de descrição da língua escrita, por considerar que tal linguagem é privilégio dos povos de cultura avançada, e, por meio dela, os prosadores e poetas de um povo fixam suas criações literárias, fruto do seu talento e da sua arte (KURY 1972, p. 11).

A Gramática Fundamental da Língua Portuguesa auxiliou como material de estudos para o público de nível médio, estudiosos e candidatos a concursos e a vestibulares que procuravam aperfeiçoar seus conhecimentos gramaticais. Kury veiculou, 
na época, um estudo que emanava da estrutura da oração e do período para o vocábulo, e deste para o fonema, em uma sequência racional.

Vale destacar que o levantamento das citações literárias da Gramática Fundamental da Língua Portuguesa abaixo apresentado não considerou a terceira e a quarta parte da obra, que tratava da morfologia e da fonologia em que a exemplificação se utilizou da linguagem culta falada. Neste âmbito, realizamos o levantamento manual do referido cânone linguístico, alocando as informações pertinentes em uma tabela contendo: apresentação nominal do autor por ordem alfabética, ano de nascimento, sigla da obra tal qual foi mencionada por Kury nas citações de sua gramática, nome da obra conforme consta nas referências do texto analisado, páginas da gramática e quantidade de citações por autor. Abaixo seguem os dados abertos para interpretações e análises.

Tabela 1: Levantamento do Cânone Linguístico-Literário da Gramática Fundamental de Kury

\begin{tabular}{|c|c|c|c|c|c|}
\hline Autor & $\begin{array}{c}\text { Ano do } \\
\text { Nascimento }\end{array}$ & $\begin{array}{c}\text { Sigla da } \\
\text { obra }\end{array}$ & $\begin{array}{l}\text { Nome da } \\
\text { obra }\end{array}$ & $\begin{array}{l}\text { Páginas da } \\
\text { gramática e } \\
\text { quantidade } \\
\text { de citações }\end{array}$ & $\begin{array}{c}\text { Total de } \\
\text { citações } \\
\text { por } \\
\text { autor }\end{array}$ \\
\hline Afonso Arinos & 1868 & PS & $\begin{array}{l}\text { Pelo Sertão, } \\
\text { Laemment\& } \\
\text { Cia }\end{array}$ & $\begin{array}{c}72(3), 73,75 \\
76,77(2), 82, \\
87\end{array}$ & 10 \\
\hline $\begin{array}{l}\text { Afonso } \\
\text { Schmidt }\end{array}$ & 1890 & & $\begin{array}{l}\text { São Paulo dos } \\
\text { meus } \\
\text { Amores, Ed. } \\
\text { (Crônica "A } \\
\text { Enfermeira") }\end{array}$ & $26(2)$ & 02 \\
\hline $\begin{array}{l}\text { Aluísio de } \\
\text { Azevedo }\end{array}$ & 1857 & Cor. & O Coruja & $\begin{array}{l}18(2), 51,56 \\
57,58,60(5)\end{array}$ & 11 \\
\hline $\begin{array}{l}\text { Augusto } \\
\text { Meyer }\end{array}$ & 1902 & $\mathrm{P}$ & Poesias & 25 & 01 \\
\hline $\begin{array}{l}\text { Augusto } \\
\text { Frederico } \\
\text { Schmidt }\end{array}$ & 1906 & $\mathrm{CN}$ & $\begin{array}{l}\text { Canto da } \\
\text { Noite }\end{array}$ & $\begin{array}{c}65,73(3), 77 \\
84\end{array}$ & 06 \\
\hline
\end{tabular}




\begin{tabular}{|c|c|c|c|c|c|}
\hline $\begin{array}{l}\text { Camilo Castelo } \\
\text { Branco }\end{array}$ & 1825 & & $\begin{array}{l}\text { A Queda dum } \\
\text { Anjo Iba } \\
\text { Mendes }\end{array}$ & 59 & 01 \\
\hline \multirow{6}{*}{$\begin{array}{l}\text { Carlos } \\
\text { Drummond de } \\
\text { Andrade }\end{array}$} & \multirow[t]{6}{*}{1902} & & $\begin{array}{l}\text { Obra não } \\
\text { identificada }\end{array}$ & $21,34,39,46$ & \multirow[t]{6}{*}{59} \\
\hline & & CA & $\begin{array}{l}\text { Contos de } \\
\text { Aprendizes }\end{array}$ & $\begin{array}{c}42(2), 46(3), \\
47(2), 51,56, \\
57,85,108\end{array}$ & \\
\hline & & Q2 & Arpoador & 55 & \\
\hline & & PI & $\begin{array}{l}\text { Passeios na } \\
\text { Ilha }\end{array}$ & $54,57,58$ & \\
\hline & & FA & $\begin{array}{l}\text { Fazendeiro } \\
\text { do Ar e } \\
\text { Poesia até } \\
\text { Agora }\end{array}$ & $\begin{array}{l}80(4) 81(5), \\
82(5), 84,85\end{array}$ & \\
\hline & & $\mathrm{BV}$ & $\begin{array}{l}\text { A Bolsa e a } \\
\text { Vida }\end{array}$ & 86 & \\
\hline $\begin{array}{l}\text { Casimiro de } \\
\text { Abreu }\end{array}$ & 1839 & & $\begin{array}{l}\text { Obra não } \\
\text { identificada }\end{array}$ & 138 & 01 \\
\hline $\begin{array}{l}\text { Cassiano } \\
\text { Ricardo }\end{array}$ & 1895 & $\mathrm{AP}$ & $\begin{array}{l}\text { Antologia } \\
\text { Poética }\end{array}$ & $\begin{array}{c}1842,53, \\
54(2), 55,56 \\
(2), 57,58(2), \\
60,61\end{array}$ & 13 \\
\hline Castro Alves & 1847 & LEA & $\begin{array}{l}\text { Língua } \\
\text { Expressão } \\
\text { Artística }\end{array}$ & 65 & 01 \\
\hline $\begin{array}{l}\text { Cecília } \\
\text { Meireles }\end{array}$ & 1901 & AP & $\begin{array}{l}\text { Antologia } \\
\text { Poética }\end{array}$ & $\begin{array}{c}14,17(5), 20 \\
(2), \\
50,53(3), \\
54(2), 55(3), \\
57(2), 58,59 \\
(3), 60,61,62\end{array}$ & 75 \\
\hline
\end{tabular}




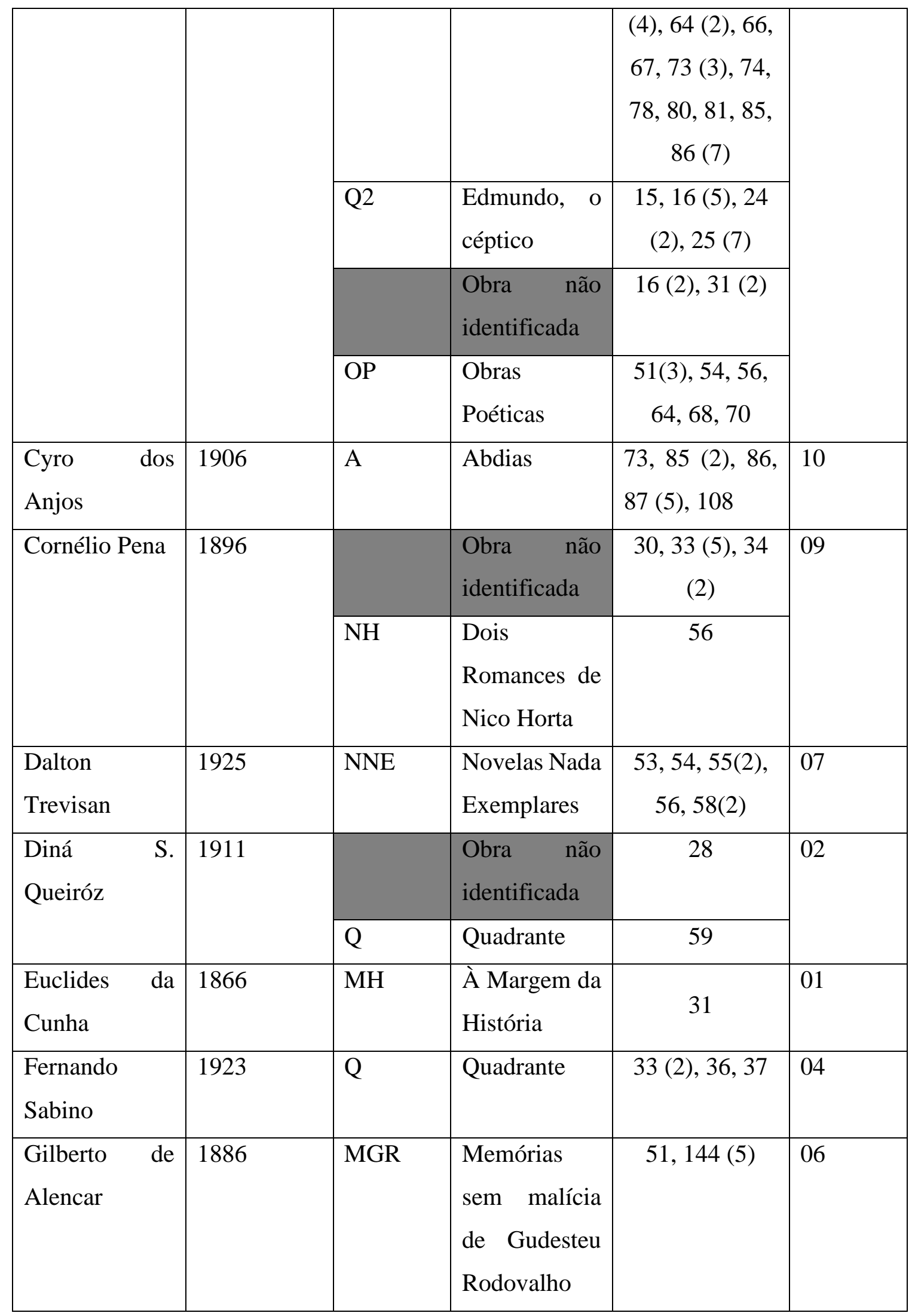




\begin{tabular}{|c|c|c|c|c|c|}
\hline $\begin{array}{l}\text { Gilberto } \\
\text { Amado }\end{array}$ & 1887 & HMI & $\begin{array}{l}\text { Histórias da } \\
\text { minha } \\
\text { Infância }\end{array}$ & $\begin{array}{c}56,66,71(3) \\
72,76,119\end{array}$ & 08 \\
\hline \multirow[t]{2}{*}{ Geir Campos } & \multirow[t]{2}{*}{1924} & \multirow[t]{2}{*}{ Met. } & Metanáutica & 17 & \multirow[t]{2}{*}{03} \\
\hline & & & $\begin{array}{l}\text { Obra não } \\
\text { identificada }\end{array}$ & 33,42 & \\
\hline \multirow[t]{3}{*}{$\begin{array}{l}\text { Graciliano } \\
\text { Ramos }\end{array}$} & \multirow[t]{3}{*}{1892} & Inf. & Infância & $\begin{array}{c}19,42, \\
50(3), 53(3), \\
54,55(3), 56, \\
57(3), 58,60 \\
(3), 63(3), 64, \\
72,81(2), 82 \\
(2), 83,85\end{array}$ & \multirow[t]{3}{*}{50} \\
\hline & & SB & $\begin{array}{l}\text { São } \\
\text { Bernardo, }\end{array}$ & $\begin{array}{l}22,59,81,82 \\
(2), 83(3), 85\end{array}$ & \\
\hline & & VS & Vidas Secas & $\begin{array}{c}33,36 \\
49(5), 50\end{array}$ & \\
\hline $\begin{array}{l}\text { Henriqueta } \\
\text { Lisboa }\end{array}$ & 1901 & Enc & $\begin{array}{l}\text { Entretenimen } \\
\text { to, }\end{array}$ & 64,70 & 02 \\
\hline $\begin{array}{l}\text { Hugo de } \\
\text { Carvalho } \\
\text { Ramos }\end{array}$ & 1895 & TB & $\begin{array}{l}\text { Tropas e } \\
\text { Boiada }\end{array}$ & $41(3), 163(12)$ & 15 \\
\hline $\begin{array}{ll}\text { Jesus } & \text { Belo } \\
\text { Galvão } & \end{array}$ & 1917 & LEA & $\begin{array}{l}\text { Língua } \\
\text { Expressão } \\
\text { Artística }\end{array}$ & 68 & 01 \\
\hline $\begin{array}{l}\text { João } \\
\text { Alphonsus }\end{array}$ & 1901 & & $\begin{array}{l}\text { Contos e } \\
\text { Novelas }\end{array}$ & 34 & 01 \\
\hline $\begin{array}{l}\text { José } \quad \text { de } \\
\text { Alencar }\end{array}$ & 1829 & Gaúcho & O Gaúcho & $59,66,77$ & 02 \\
\hline $\begin{array}{l}\text { José Lins do } \\
\text { Rego }\end{array}$ & 1901 & MR & $\begin{array}{l}\text { O Moleque } \\
\text { Ricardo }\end{array}$ & 28 & 06 \\
\hline
\end{tabular}




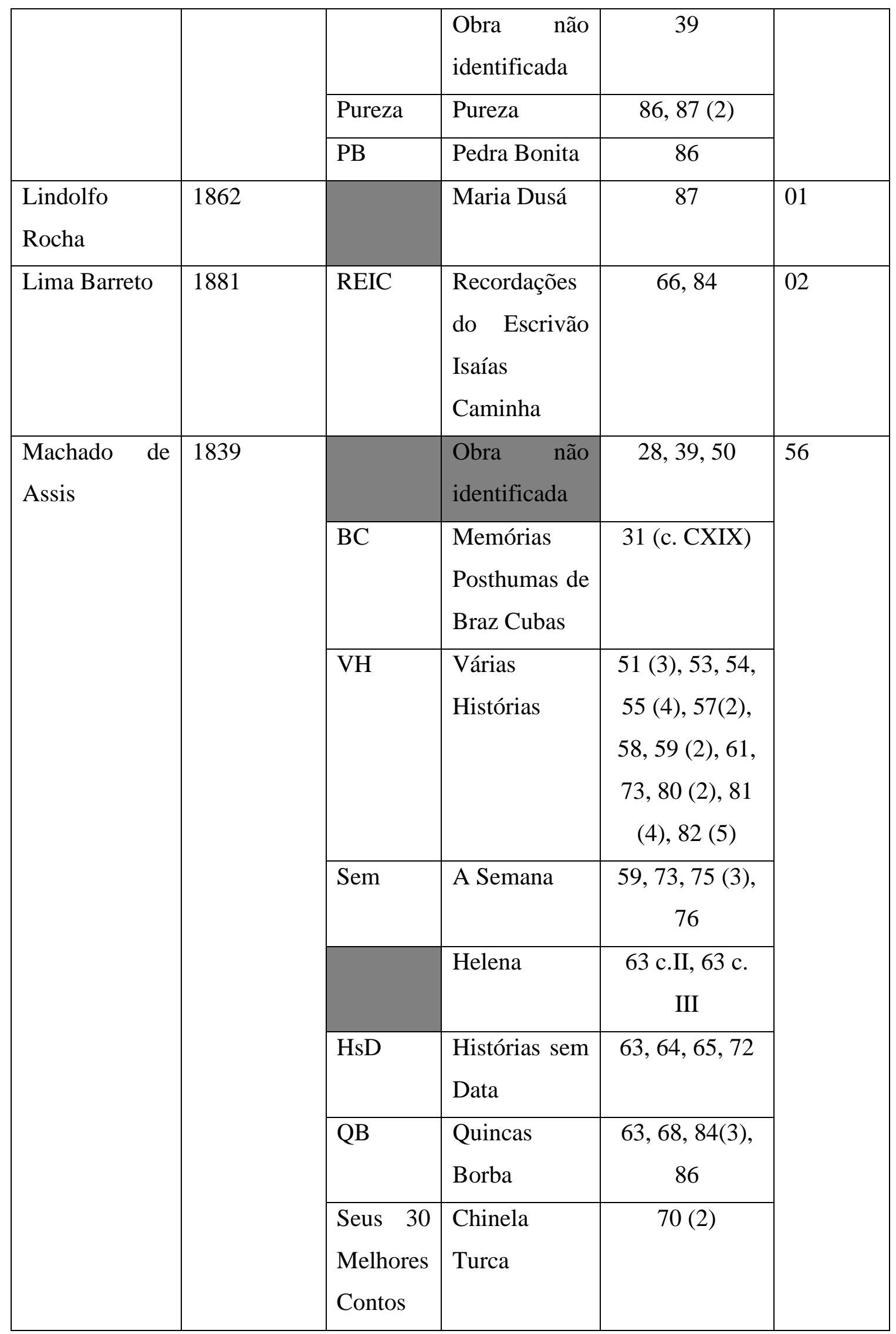




\begin{tabular}{|c|c|c|c|c|c|}
\hline & & $\mathrm{RCV}$ & $\begin{array}{l}\text { Relíquias de } \\
\text { Casa Velha }\end{array}$ & 90 & \\
\hline \multirow[t]{3}{*}{$\begin{array}{l}\text { Manuel } \\
\text { Bandeira }\end{array}$} & \multirow[t]{3}{*}{1886} & $\mathrm{PP}$ & $\begin{array}{l}\text { Poesia e } \\
\text { Prosa }\end{array}$ & $81(2), 82$ & \multirow[t]{3}{*}{05} \\
\hline & & Q2 & Visita & 14 & \\
\hline & & Q2 & Chuchu & 67 & \\
\hline $\begin{array}{ll}\text { Mário de } \\
\text { Andrade }\end{array}$ & 1886 & & $\begin{array}{l}\text { Obra não } \\
\text { identificada }\end{array}$ & 48 & 01 \\
\hline $\begin{array}{l}\text { Marques } \\
\text { Rebelo }\end{array}$ & 1907 & SAP & $\begin{array}{l}\text { Stela me } \\
\text { Abriu a Porta }\end{array}$ & 60 & 01 \\
\hline $\begin{array}{l}\text { Marquês de } \\
\text { Maricá }\end{array}$ & 1773 & & $\begin{array}{l}\text { Máximas, } \\
\text { Pensamentos } \\
\text { e Reflexões }\end{array}$ & 58 & 01 \\
\hline \multirow[t]{4}{*}{$\begin{array}{l}\text { Monteiro } \\
\text { Lobato }\end{array}$} & \multirow[t]{4}{*}{1882} & & $\begin{array}{l}\text { Obra não } \\
\text { identificada }\end{array}$ & 31,39 & \multirow[t]{4}{*}{07} \\
\hline & & Fáb & Fábulas & 60 & \\
\hline & & Ur. & $\begin{array}{l}\text { Urupês, } \\
\text { outros Contos } \\
\text { e Coisas }\end{array}$ & $81,82,83$ & \\
\hline & & & $\begin{array}{l}\text { O reformador } \\
\text { do mundo }\end{array}$ & 184 & \\
\hline Nélida Piñón & 1937 & & $\begin{array}{l}\text { Madeira Feita } \\
\text { Cruz }\end{array}$ & $\begin{array}{c}26,31,33,39 \\
\text { (2) }\end{array}$ & 05 \\
\hline Olavo Bilac & 1865 & & $\begin{array}{l}\text { Poesias } \\
\text { Infantis }\end{array}$ & 31 & 01 \\
\hline Osman Lins & 1924 & Vis. & O Visitante & $\begin{array}{l}20,58 \\
37(2)\end{array}$ & 04 \\
\hline $\begin{array}{l}\text { Raquel de } \\
\text { Queirós }\end{array}$ & 1910 & $\mathrm{BP}$ & $\begin{array}{l}\text { O Brasileiro } \\
\text { Perplexo }\end{array}$ & 27 & 01 \\
\hline $\begin{array}{l}\text { Ricardo } \\
\text { Cassiano }\end{array}$ & 1895 & AP & $\begin{array}{l}\text { Antologia } \\
\text { Poética }\end{array}$ & 18 & 01 \\
\hline
\end{tabular}




\begin{tabular}{|l|l|l|l|c|l|}
\hline Rubem Braga & 1913 & BA & $\begin{array}{l}\text { A Borboleta } \\
\text { Amarela }\end{array}$ & 87 & 01 \\
\hline Rui Barbosa & 1849 & & $\begin{array}{l}\text { Obra não } \\
\text { identificada }\end{array}$ & $71(4)$ & 04 \\
\hline $\begin{array}{l}\text { Theodoro } \\
\text { Henrique } \\
\text { Mauer Júnior }\end{array}$ & 1906 & IFP & $\begin{array}{l}\text { O Infinito } \\
\text { Flexionado } \\
\text { Português }\end{array}$ & $(3)$, & 07 \\
\hline $\begin{array}{l}\text { V.L. Cardoso } \\
\text { Naldemar }\end{array}$ & 1901 & JSV & $\begin{array}{l}\text { Obra não } \\
\text { identificada }\end{array}$ & 31 & 01 \\
Versiani dos & & Serra Verde & 73 & 01 \\
\hline $\begin{array}{l}\text { Anjos } \\
\text { Alvarenga } \\
\text { Borges }\end{array}$ & 1922 & & Ofício Lírico & 39 & 01 \\
\hline
\end{tabular}

De acordo com os pressupostos discutidos anteriormente, no que tange ao ideal de perfeição da língua escrita exigida pelo modelo tradicional, tomemos as citações literárias escolhidas por Kury como abonações representativas de uma competência linguística com nível de excelência, consagrada por escritores de referência da língua literária moderna do Brasil, reconhecidos pela comunidade acadêmica.

As exemplificações descritas do cânone literário na obra abonam um total de 384 (trezentos e oitenta e quatro) citações e 11 (onze) frases escritas por gramáticos e filólogos renomados, como Mattoso Câmara Júnior. Se compararmos estudos semelhantes realizados em outras gramáticas da mesma época, observaremos que o total de exemplificação do cânone literário da obra em questão é bem menor, frente ao modelo escolhido para a construção da obra, dividida em quatro partes, contendo um total de 206 (duzentas e seis) páginas.

Além disso, ela pode ser considerada relativamente concisa, se comparada às de referência para a época como a Gramática Normativa da Língua Portuguesa de Rocha Lima, $15^{a}$ edição, publicada em 1972, contendo 659 páginas, a Gramática do Português 
Contemporâneo, $1^{\text {a }}$ edição, publicada em 1970, com 512 páginas ou a Gramática da Língua Portuguesa, $1^{\text {a }}$ edição, lançada em 1972 com um total de 654, ambas de Celso Cunha.

Observamos ainda as seguintes informações:

Dos autores

- Num total de 48 (quarenta e oito), temos 47 (quarenta e sete) brasileiros e somente 01 (um) português, Camilo Castelo Branco;

- 43 (quarenta e três) são do sexo masculino e 05 (cinco) do sexo feminino;

- A critério de curiosidade, uma das autoras não aparece na relação de autores e livros citados na obra, sendo Dinah Silveira de Queiróz. Kury utilizou duas citações literárias da autora, ambas retiradas do Quadrante e transcritas nas páginas 28 e 59 , respectivamente;

- Em relação ao ano de nascimento dos autores, observamos uma diferença cronológica entre o século XVIII e XX: há 01 (um) entre 1700 a 1800, 24 (vinte e quatro) entre 1801 a 1900 e 22 (vinte e dois) a partir de 1901.

\section{Das citações literárias}

- No total de 384 (trezentos e oitenta e quatro), temos 297 (duzentos e noventa e sete) de autores homens e 87 (oitenta e sete) de autoras mulheres;

- O corpus de exemplificação apresenta uma diferença cronológica de um século.

Do exemplário completo, merecem destaque quatro autores brasileiros que correspondem a 55\% das citações literárias na obra, sendo respectivamente: Cecília Meireles (20\%); Machado de Assis (14\%); Graciliano Ramos (13\%) e Carlos Drummond de Andrade (8\%).

Traduzindo em formato estatístico, visualizamos o seguinte gráfico demonstrativo: 
Estudo sobre o uso do cânone linguístico-literário na Gramática Fundamental da Língua Portuguesa, de Adriano da Gama Kury

Gráfico 1: Levantamento em porcentagem das citações dos autores na Gramática Fundamental de Kury

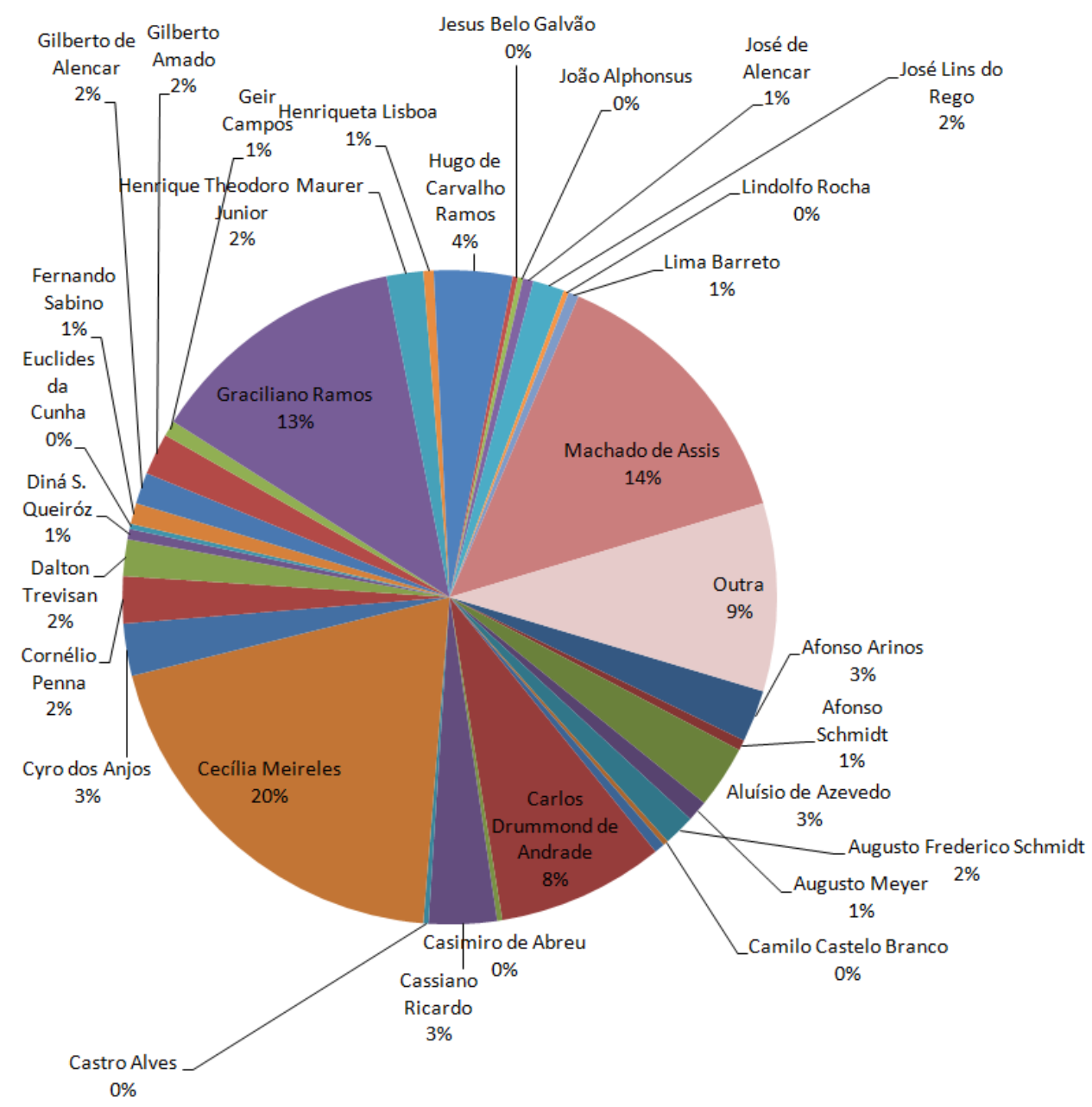

Fonte: Autora

Lendo esse inventário, observamos a supremacia numérica de Cecília Meireles com $20 \%$ das citações, além da presença de outras quatro autoras femininas que juntas correspondem a mais de $26 \%$ do cânone literário selecionado para compor esta obra.

Cabe mencionar que ela não foi citada como referência de cânone literário em gramáticas de relevância publicadas na mesma década, como a Gramática Normativa da Língua Portuguesa (1972) de Rocha Lima e a Moderna Gramática Portuguesa (1982) de Bechara; mas estava presente nas três versões das gramáticas de Celso Cunha, sendo elas: a Gramática do Português Contemporâneo (1970), Gramática da Língua Portuguesa 
(1972) e Nova Gramática do Português Contemporâneo (1985). Certamente ficará a impressão de que o autor da Gramática Fundamental da Língua Portuguesa - Nível Médio dedicou a Cecília Meireles uma reverência linguística digna de registro. Outra questão que merece destaque é a intenção inovadora de utilizar autores contemporâneos da literatura brasileira para o ano de 1972.

\section{CONSIDERAÇÕES FINAIS}

A Gramática Fundamental da Língua Portuguesa de Adriano da Gama Kury, assim como os manuais de língua publicados na mesma época, sofreu influência das diretrizes fixadas na NGB e na relacionada Lei $n^{\circ} 5692 / 71$. Portanto, a execução deste tipo de pesquisa oportuniza também a caracterização das influências históricas na gramaticografia brasileira e, em consequência, o retrato da Língua Portuguesa usada em um contexto determinado.

Cabe aludir que, para a conjuntura histórica em que a obra foi publicada, é considerada inovadora no tocante ao corpus selecionado e a inserção de novas fontes literárias, linguagem culta falada e corpus ampliado em relação aos manuais clássicos. Kury valeu-se, nas primeiras partes de sua gramática, da modalidade escrita literária contemporânea; já nas últimas, recorreu à linguagem falada pelas pessoas consideradas cultas na década de 1970 nas cidades do Rio de Janeiro e São Paulo.

Logo, ao realizarmos o inventário do Cânone Linguístico-Literário escolhido por Kury como abonações representativas de excelência linguística, observamos que o autor abandonou a fidelidade e a homogeneidade do corpus com a descrição da língua escrita literária, mas não rompeu definitivamente com o modelo tradicional, pois ainda privilegiou a apresentação de um corpora de descrição da língua escrita. Nessa perspectiva, reconhecemos que o trecho escolhido de um autor serve não apenas para comprovar a regra ou a exposição gramatical, mas também para atribuir ao autor um nível de excelência diante do eventual leitor da obra teórica (HENRIQUES 1998, p. 26).

A partir deste levantamento, abrem-se variados campos interpretativos que poderão aguçar a continuidade deste estudo por outros pesquisadores interessados nesta temática. Disponibilizamos ao leitor, como informação adicional, uma tabela em anexo, 
com a transcrição de citações não identificadas na obra e utilizadas na exemplificação dos fatos da língua, que ficarão disponíveis para novas interpretações e análises.

\section{Referências}

AZEREDO, J. C. Gramática Houaiss da língua portuguesa. 3.ed. - São Paulo: Publifolha, 2010.

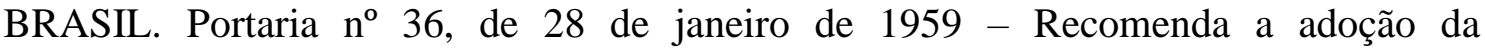
Nomenclatura Gramatical Brasileira. Brasília,1959.

BRASIL. Lei n 5692, de 11 de agosto de 1971. Fixa as Diretrizes e Bases da Educação. Brasília,1971.

BECHARA, E. Moderna gramática portuguesa. Edição revista e ampliada. Rio de Janeiro, Editora Lucerna, 1999. 2003. Moderna gramática portuguesa. 37. ed. rev. e ampl. Rio de Janeiro: Lucerna, Moderna gramática portuguesa. 38. ed. rev. ampl. Rio de Janeiro: Nova Fronteira, 2015.

CAVALIERE, R. Fonologia e morfologia na gramática científica brasileira. Niterói, Editora da Universidade Federal Fluminense, 2000.

Uma Proposta de Periodização dos Estudos Linguísticos no Brasil. Alfa. Revista de Linguística, v. 45, 2001, p. 49-69. 2014.

A gramática no Brasil: ideias, percursos e parâmetros. Rio de Janeiro: Lexikon,

CARRETER, F. L. Diccionario de Términos Filologicos. Madrid, Gredos, 1974.

CORRÊA, A. A. Historiografia, cânone e autoridade. In: Anais do CELLIP (Congresso de Estudos Linguísticos e Literários do Paraná). Umuarama, p. 323-328, 1995.

COSERIU, E. Do sentido do ensino da língua literária. Confluência, Rio de Janeiro, Liceu Literário Português, n. ${ }^{\circ}$ 5, p. 37-50, 1993.

Sobre o ensino do idioma nacional: problemas, propostas e perspectivas. Confluência, Rio de Janeiro, Liceu Literário Português, Tradução de Evanildo Bechara, n. ${ }^{\circ} 23$, p. 71-79, 2002.

CUNHA, C. F.; CINTRA, L. F. L. Nova gramática do português contemporâneo. Rio de Janeiro, Editora Nova Fronteira, 2001. 
FARACO, C. A.; VIEIRA, F. E. Gramáticas brasileiras: com a palavra, os leitores. São Paulo: Parábola Editorial, 2016.

FIORIN, J. L. Introdução ao pensamento de Bakhtin. São Paulo: Contexto, 2017.

HENRIQUES, C. C. Era uma vez um livro... Breve história da Moderna Gramática Portuguesa, de Evanildo Bechara. In: Denise Salim Santos; Flávio de Aguiar Barbosa; Sheila Hue. (Org.). O Sentimento da Língua: homenagem a Evanildo Bechara 90 anos. 1.ed. Rio de Janeiro: Nau, 2020, v. 1, p. 69-80.

.; JADEL, J. A. F.; BRASIL, P. C. S. Moderna Gramática, de Evanildo Bechara: alterações entre as edições 37 e 38. Revista da Academia Brasileira de Filologia, v. 23, p. 35-52, 2019.

O Cânone Lingüístico-Literário nas Gramáticas de Celso Cunha. Filologia e Lingüística Portuguesa, São Paulo, v. 6, p. 115-159, 2004.

O Cânone Linguístico-Literário segundo a Gramática Normativa da Língua Portuguesa, de Carlos Henrique da Rocha Lima. Revista da Academia Brasileira de Filologia, Rio de Janeiro, v. 2, n.2, p. 44-52, 2003.

A Canonização Lingüístico-Literária na Moderna Gramática Portuguesa, de Evanildo Bechara. Idioma (UERJ), Rio de Janeiro, v. 20, p. 25-36, 1998.

KURY, A. G. Gramática Fundamental da Língua Portuguesa - Ensino Médio. SP: Ed. Lisa - Livros Irradiantes S.A., 1972. Agir, 1959.

Pequena Gramática para explicação da nova Nomenclatura gramatical. RJ: Ed.

MATTOS E SILVA, R. V. Tradição Gramatical e Gramática Tradicional. São Paulo, Contexto, 2000.

NEVES, M. H. M. Gramática de usos do português. São Paulo: Editora UNESP, 2000. A gramática: história, teoria e análise, ensino. São Paulo: Editora UNESP, 2002.

.; OLIVEIRA, L. A. (Org.). Estudos do discurso: perspectivas teóricas. São Paulo: Parábola Editorial, 2013.

PERRONE-MOISÉS, L. Altas literaturas: escolha e valor na obra crítica de escritores modernos. São Paulo: Companhia das Letras, 1998.

SAVIANI, D. A nova lei da educação: trajetória, limites e perspectivas. Campinas, SP: Autores Associados, 1997. 
SOARES, L. A. A. Cinco gramáticas contemporâneas: leituras e concepções. Revista DLCV - Língua, Linguística \& Literatura. Paraíba: UFP, v. 13, nº 2, jul./dez. 2017, p. 4864.

ROCA-PONS, J. Introducción a la Gramática. Barcelona, Teide, 1976.

ROCHA LIMA, C. H. Gramática normativa da língua portuguesa. Rio de Janeiro: José Olympio, 1992.

STEFANINI, J. Histoire de La Grammare. Paris, CNRS, 1994.

TRASK, R. L. A Dictionary of Grammatical Terms in Linguistics. London/New York, Routledge, 1993.

VIEIRA, F. E. A gramática tradicional: história crítica. São Paulo: Parábola, 2018.

VOGT, Carlos. Linguagem, pragmática e ideologia. São Paulo: Hucitec, 1989.

Recebido em: 24/04/2021

Aceito em: 08/09/2021

\section{Anexos}

Cabe mencionar que tomamos como citações os trechos das obras que estão entre aspas ou que não apresentam especificação de autoria. As demais exemplificações são consideradas de Adriano da Gama Kury. Assim, apresentamos como informação complementar a tabela abaixo, contendo a transcrição de citações não identificadas, retiradas da primeira e segunda parte da obra Gramática Fundamental da Língua Portuguesa de Kury a fim de possibilitar novas investigações.

\section{Inventário das citações sem identificação de autoria, na primeira parte da obra}

\begin{tabular}{|l|l|}
\hline $\begin{array}{l}\text { Páginas da } \\
\text { gramática }\end{array}$ & Trechos \\
\hline 13 & "Amor com amor se paga". \\
\hline 13 & "Minha terra tem palmeiras". \\
\hline 14 & "Eletricista". \\
\hline
\end{tabular}




\begin{tabular}{|c|c|}
\hline 14 & "Silêncio". \\
\hline 14 & $\begin{array}{l}\text { "Somos seus admiradores e seus discípulos. Desejamos conversar com } \\
\text { o senhor: pode receber-nos? Pois não. Hoje mesmo, às quatro horas". }\end{array}$ \\
\hline 15 & "Mas Edmundo era céptico". \\
\hline 15 & "As pessoas aborreciam-se e chamavam-no de teimoso". \\
\hline 15 & $\begin{array}{l}\text { "Ele queria quebrar com os dentes os caroços de ameixa, para chupar } \\
\text { um melzinho que há lá dentro". }\end{array}$ \\
\hline 15 & "E só não morreu por que o jardineiro andava perto". \\
\hline 19 & "Sim ele é meu tutor". \\
\hline 25 & "Eles eram, eles diziam". \\
\hline 25 & "Uma pessoa lhe dizia". \\
\hline 25 & "Tentaram enganá-lo". \\
\hline 27 & "a gente ouve falar", "ouve-se falar". \\
\hline 28 & "Não há problemas insolúveis" \\
\hline 28 & "Não existem problemas insolúveis" \\
\hline 47 & "reservou-lhe", "reservou-nos".... \\
\hline 56 & "Só o coração [de quem ama] é capaz de compreendê-la" \\
\hline 56 & "Chegou à vez [de quantos esperavam]" \\
\hline 56 & "Os primeiros funcionários [ a serem transferidos] protestaram." \\
\hline 58 & "Dançava [conforme tocasse a música]." \\
\hline 58 & "Devem citar-se os autores [consoante escrevem]" \\
\hline 59 & $\begin{array}{l}\text { "Quando o homem vive [segundo costuma], e não [segundo Deus } \\
\text { manda], é semelhante ao demônio." }\end{array}$ \\
\hline 67 & "V. Ex. a tem sido muito generoso." \\
\hline 67 & "Espero que tu e todos em casa estejam bem" \\
\hline 69 & $\begin{array}{l}\text { "Viver é lutar." } \\
\text { "Houve festas." } \\
\text { "Amanheceu lentamente." } \\
\text { "Trabalhar muito fatiga." }\end{array}$ \\
\hline 70 & $\begin{array}{l}\text { "Para ouvir melhor, uso um aparelho auditivo." } \\
\text { "Para ouvir melhor, usa um aparelho auditivo." }\end{array}$ \\
\hline 72 & $\begin{array}{l}\text { "Honrar pai e mãe." } \\
\text { "Deixá-lo em paz." }\end{array}$ \\
\hline 74 & $\begin{array}{l}\text { "Não nos deixeis cair em tentação." } \\
\text { "Fê-los entrar." } \\
\text { "Mandou-os fazer leis." } \\
\text { "Mandei-os sair." } \\
\text { "Deixai [vir a mim as criancinhas]." } \\
\text { "Vi-[te brilhar entre as pedras]." }\end{array}$ \\
\hline 76 & $\begin{array}{l}\text { "Qual caminho tomaram? Lembras-te? Foram logo direto ao engenho? } \\
\text { Quer-me parecer que não. Vi tomarem para as bandas de Nazaré." }\end{array}$ \\
\hline 79 & $\begin{array}{l}\text { "Ele se guia pelas marcas do carro na areia." } \\
\text { "Ele seguia pelas marcas do carro na areia." } \\
\text { "Me diga", "Te adoro", "Diga-me", "Adoro-te." }\end{array}$ \\
\hline 82 & $\begin{array}{l}\text { "Deus te proteja." } \\
\text { "Bons ventos o levem." }\end{array}$ \\
\hline
\end{tabular}




\begin{tabular}{|c|c|}
\hline 122 & "A madre superiora era enérgica." \\
\hline 128 & $\begin{array}{l}\text { "O jacarandá era a árvore mais alta do bosque; era o mais alto de todos." } \\
\text { "A margarida é a planta menos desenvolvida do jardim; é menos } \\
\text { desenvolvida de todas." }\end{array}$ \\
\hline 129 & $\begin{array}{l}\text { "Minha turma tem trinta alunos; Abel é o primeiro nome da chamada, e } \\
\text { Zulmira o trigésimo." } \\
\text { "Trinta é o dobro de quinze e o triplo de dez." } \\
\text { "Dez é um terço de trinta e a metade de vinte." }\end{array}$ \\
\hline 131 & $\begin{array}{l}\text { "Eu sou professor." } \\
\text { "Nós todos somos alunos." } \\
\text { "Agora você pode sair." } \\
\text { "Para onde a senhora vão agora?" } \\
\text { "Impressionante a força dos seus músculos." } \\
\text { "Aos poucos foi conseguindo respirar, até se acostumar com aquele } \\
\text { ambiente." } \\
\text { "Aclamava-se e tentava compreender que aquele mistério fazia parte da } \\
\text { sua transformação." } \\
\text { "A muito custo ela abriu os olhos." } \\
\text { "Pensou em outras coisas." } \\
\text { "A menina sentiu-se triste." }\end{array}$ \\
\hline 132 & $\begin{array}{l}\text { "Eu espero." } \\
\text { "O professor voltou-se para mim." } \\
\text { "Tu não me sais da lembrança.", } \\
\text { "Você pode alcançar liberdade." } \\
\text { "O senhor vai desculpar." } \\
\text { "Ele pôs a cabeça fora do carro." } \\
\text { "Encontrei um amigo e o trouxe até aqui." } \\
\text { "Eu lhe tinha feito uma promessa." }\end{array}$ \\
\hline 134 & $\begin{array}{l}\text { "Tu deves estudar." } \\
\text { "Um lavrador pedi licença para falar a Vossa Majestade." }\end{array}$ \\
\hline 139 & $\begin{array}{l}\text { "Esta terra é minha." } \\
\text { "Esta terra é bela." }\end{array}$ \\
\hline 140 & $\begin{array}{l}\text { "Meus livros estão bem conservados, mas os de José, não." } \\
\text { "O (= aquele) que nada aprende nada sabe." } \\
\text { "Dê-me esse livro." } \\
\text { "Esta é a diretora da Escola." } \\
\text { "Quem espera sempre alcança." } \\
\text { "Uma pessoa qualquer." } \\
\text { "Todos cantam sua terra." } \\
\text { "Outro dia fui a São Paulo." } \\
\text { "Tem tantas belezas minha terra..." }\end{array}$ \\
\hline 141 & $\begin{array}{l}\text { "Muitos precisam aprender; poucos sabem ensinar." } \\
\text { "Quantos desejam ter o que outros aborrecem!"” } \\
\text { "Enquanto uns estudam outros ensinam." } \\
\text { "Você fica de pé, os demais sentem-se." } \\
\text { "Quero mais!" } \\
\text { "Quanto demoraste!" }\end{array}$ \\
\hline
\end{tabular}




\begin{tabular}{|c|c|}
\hline & $\begin{array}{l}\text { "O mais é secundário." } \\
\text { "Não sei que dizer." } \\
\text { "Muitos alunos faltaram hoje." } \\
\text { "Trouxe quantas frutas pôde." } \\
\text { "Carregas livros demais." } \\
\text { "Ouviu tais elogios, que enrubesceu." } \\
\text { "Que susto levei!"” } \\
\text { "Que torturas padeci!" } \\
\text { "Quero mais aulas." }\end{array}$ \\
\hline 142 & $\begin{array}{l}\text { "Que desejas?" } \\
\text { "Que livro é esse?" } \\
\text { "Qual foi o primeiro Presidente da República?" } \\
\text { "Qual esporte preferes?" } \\
\text { "Quem vem lá?" } \\
\text { "Quantos trouxestes hoje?" } \\
\text { "Quantos livros tens?" } \\
\text { "Zoroastro é um amigo que se vai tornando gerente de minha casa, onde } \\
\text { põe e dispõe à vontade." } \\
\text { "Naquela cidade havia um médico novo, cuja casa era arrumada por um } \\
\text { menino chamado Filogônio, o qual tinha as pernas tortas." }\end{array}$ \\
\hline 143 & $\begin{array}{l}\text { "Zoroastro era um amigo a quem (= ao qual) confiava o arranjo de tudo } \\
\text { quanto (=que) precisava." }\end{array}$ \\
\hline 148 & $\begin{array}{l}\text { "Quando cheguei, a aula já tinha começado (ou havia começado); } \\
\text { começará dez minutos antes." } \\
\text { "Embora a aula já tivesse começado (ou houvesse começado), o } \\
\text { professor permitiuque eu entrasse, por ter achado justo o motivo do } \\
\text { atraso" }\end{array}$ \\
\hline 149 & $\begin{array}{l}\text { "As dez horas a prova já terá (ou haverá) terminado; se já tiver (ou } \\
\text { houver) acabado, venha avisar-me." } \\
\text { "Daqui a meia hora o inspetor já terá (ou haverá) chegado; quando ele } \\
\text { chegar, já terei (ou haverei) aprontado tudo." } \\
\text { "A professora prometeu que quem tirasse boa nota ganharia um prêmio." } \\
\text { "O inspetor tinha avisado que chegaria às dez horas." } \\
\text { "Se eu obtivesse o empréstimo, compraria um apartamento." } \\
\text { "Estava previsto que, às dez horas, a prova já teria (ou haveria) } \\
\text { terminado." } \\
\text { "Se eu tivesse obtido o empréstimo teria (ou haveria) comprado o } \\
\text { apartamento." } \\
\text { "Eu o teria (ou haveria) esperado ontem, caso não tivesse } \\
\text { compromisso." }\end{array}$ \\
\hline 150 & $\begin{array}{l}\text { "É preferível morrer (=a morte) a viver (=à vida de) escravo." } \\
\text { "Viver é lutar." } \\
\text { "É honroso ter (ou haver) lutado pela pátria." } \\
\text { "É conveniente estudares." } \\
\text { "Tiraste boa nota por teres (ou haveres) estudado." } \\
\text { "Estudando aprenderás." } \\
\text { "Tendo estudado pelo estudo tirou boas notas." }\end{array}$ \\
\hline
\end{tabular}




\begin{tabular}{|c|c|}
\hline 151 & $\begin{array}{l}\text { "Que vais fazer à noite?" } \\
\text { "Vou ler este livro." }\end{array}$ \\
\hline 163 & $\begin{array}{l}\text { "Mais negra que o carvão." } \\
\text { "Defendia os filhos muito corajosamente". }\end{array}$ \\
\hline 165 & $\begin{array}{l}\text { "Planaltina já estava nos mapas, muito antes de Brasília." } \\
\text { "Cada ano avançava mais perto, pertinho." } \\
\text { "Estavam mal, agora estão pior." }\end{array}$ \\
\hline 167 & $\begin{array}{l}\text { "Correm a fim de ver." } \\
\text { "O caixão vai em cima de um banco." } \\
\text { "O sol fura através da folhagem." } \\
\text { "O cemitério fica à beira da água." }\end{array}$ \\
\hline 169 & $\begin{array}{l}\text { "O vento carregava as folhas por sobre os telhados." } \\
\text { "Tirei o livro de dentro da pasta." } \\
\text { "Passei por entre as poças d'água sem molhar-me." }\end{array}$ \\
\hline 170 & $\begin{array}{l}\text { "Uma aluna saiu." } \\
\text { "Os alunos devem dirigir-se a aquela sala." }\end{array}$ \\
\hline 171 & "Vou ao colégio todas as manhãs." \\
\hline 175 & $\begin{array}{l}\text { "Aos meus alunos e às minhas alunas desejo boa sorte." } \\
\text { "A meus alunos e a minhas alunas desejo boa sorte." } \\
\text { "Cheguei a minha sala (ou à minha sala) atrasado." } \\
\text { "Cheguei a meu escritório (ou ao meu escritório)..." } \\
\text { "Cada um deve dirigir-se a (ou à) nossa consciência democrática." } \\
\text { "Há muito tempo você não comparece a (ou às) nossas aulas." } \\
\text { "Veio a (ou à) nossa reunião." } \\
\text { "Veio a nossas reuniões." }\end{array}$ \\
\hline 177 & $\begin{array}{l}\text { "As patativas e os bicudos também cantavam." } \\
\text { "Nem as patativas nem os bicudos lhe chegavam aos pés." } \\
\text { "As jabuticabas eram raras, mas saborosas." } \\
\text { "Correu a tia Naninha para me consolar, mas não foi possível." } \\
\text { "(Ou) Andávamos pela horta, ou corríamos para a beira do rio." } \\
\text { "Queria-o longe de todos os perigos; deixava-os, pois (ou portanto, ou } \\
\text { então, ou assim) fora do alcance dos gatos." } \\
\text { "José Joaquim me regalou com um canário, de modo que (ou logo, } \\
\text { portanto) se revelou meu amigo." } \\
\text { "Tenha paciência, José, que ele há de voltar." } \\
\text { "E perdi o meu querido canário..." }\end{array}$ \\
\hline 178 & $\begin{array}{l}\text { "Os alunos foram dispensados porque era feriado." } \\
\text { "Os soldados haviam sido treinados para que obedecessem." } \\
\text { "Em caso de desobediência, eram punidos." } \\
\text { "caso (ou se) desobedecessem" } \\
\text { "Eles descobriram que podiam evitar choques." }\end{array}$ \\
\hline 179 & $\begin{array}{l}\text { "Como estava chovendo, não saí." } \\
\text { "Demorei porque perdi o ônibus." } \\
\text { "Voltei à casa paterna como (ou assim como, ou tal como, ou qual, ou } \\
\text { tal qual) a ave volta ao ninho antigo." } \\
\text { "Embora (ou ainda que, ou mesmo que, etc) estudasse, não tirou boa } \\
\text { nota." } \\
\text { "Inteligente que sejas, precisas estudar." }\end{array}$ \\
\hline
\end{tabular}




\begin{tabular}{|l|l|}
\hline & $\begin{array}{l}\text { "Nem que precise, não lhe pedirei favores." } \\
\text { "Por mais que estude, pouco aprende." } \\
\text { "Ganharás um prêmio se estudares." } \\
\text { "Eles não prosseguirão as obras sem que lhes pague." }\end{array}$ \\
\hline 180 & $\begin{array}{l}\text { "Cada um colhe conforme semeia." } \\
\text { "Ele estudou bastante, de sorte que fez bom exame." } \\
\text { "Estudou tanto, que cansou." } \\
\text { "Dava-nos tais respostas, que nos espantava." } \\
\text { "Eltava tamanhos gritos, que meus ouvidos doíam." } \\
\text { "Tocou o sinal para que a prova começasse." } \\
\text { "Pouco faltou que ele tirasse a nota máxima." } \\
\text { "Rezai, porque não entreis em tentação." } \\
\text { "Á medida que se aproximava a hora da prova, o nervosismo } \\
\text { aumentava." } \\
\text { "Quanto mais se agitava, mais perto ficava." }\end{array}$ \\
\hline 181 & $\begin{array}{l}\text { "Quando o diretor chegar, começará a prova." } \\
\text { "Enquanto guardavam, todos e mantinham atentos." } \\
\text { "Apenas ele entrou, houve um movimento geral de satisfação." } \\
\text { "Pensa bem primeiro que escrevas as respostas." } \\
\text { "Muito tempo já havia passado que a prova começara." } \\
\text { "Do latim não tenho lá muita certeza." } \\
\text { "Do latim não tenho muita certeza." }\end{array}$ \\
\hline 187
\end{tabular}

